\title{
Influence of ginseng cultivation under larch plantations on plant diversity and soil properties in Liaoning Province, Northeast China
}

LIU Wei-wei',2 (D)http://orcid.org/oooo-0oo1-5670-606X; e-mail: abc7529703@163.com

LIU Mou-cheng1* (D)http://orcid.org/oooo-0oo2-4444-3482; e-mail: liumc@igsnrr.ac.cn

LI Wen-hua1 (D)http://orcid.org/oooo-0oo1-9614-4890; e-mail: liwh@igsnrr.ac.cn

ZENG Fan-shun3 (Dhttp://orcid.org/oooo-0oo2-1641-0560; e-mail: fanshun_zeng@163.com

QU Yi3 (D)http://orcid.org/oooo-0oo2-2489-1050; e-mail: quyio929@163.com

* Corresponding author

1 Institute of Geographic Sciences and Natural Resources Research, Chinese Academy of Sciences, Beijing 10o101, China

2 University of Chinese Academy of Sciences, Beijing 10oo49, China

3 Liaoning Academy of Forestry, Shenyang 110032, China

Citation: Liu WW, Liu MC, Li WH, et al. (2016) Influence of ginseng cultivation under larch plantations on plant diversity and soil properties in Liaoning Province, Northeast China. Journal of Mountain Science 13(9). DOI: 10.1007/s11629-015-3753-x

(C) Science Press and Institute of Mountain Hazards and Environment, CAS and Springer-Verlag Berlin Heidelberg 2016

\begin{abstract}
Currently, transforming the mode of forest management and developing multiple forest management practices are actively encouraged in China. As one forest management type, ginseng cultivation under larch plantations has been developed significantly in the east of Liaoning Province. However, research on the influence of the ecological environment for this mode of production is still deficient. Based on this, our study compares the plant diversity and soil properties in the ginseng cultivation under larch plantations (LG) with larch plantations (LP) and natural secondary forests (SF). First, we randomly selected three plots for each of the three stand types which have similar stand characteristics; then, we carried out a plant diversity survey and soil sampling in each of the nine plots. The results show that no significant difference was found in plant diversity between LG and LP, but the
\end{abstract}

Received: 16 October 2015

Revised: 15 March 2016

Accepted: 7 April 2016 evenness of herbs was significantly lower in LG than LP. No obvious changes in soil physical properties were found in LG, but a significant decrease in most of the soil nutrient content was presented in LG. Furthermore, we found a correlation between plant diversity $\left(\mathrm{H}^{\prime}\right)$ and soil properties in the three kinds of stand types, especially between herbaceous plant diversity and soil properties. We conclude that ginseng cultivation under larch plantations has no obvious effect on plant diversity, except the herbaceous evenness. Soil fertility can be depleted significantly in LG, but physical structures are not affected. Moreover, maintaining the diversity of herbaceous plants and controlling the density of ginseng cultivation in LG by farmers are important for the ecological environment. Based on this study and its good comprehensive benefits and with the support of policy, we think this forest management type should be promoted moderately in the region.

Keywords: Forest management; Ginseng cultivation; 
Larch plantations; Secondary forests; Plant diversity; Soil properties; Changbai Mountain

\section{Introduction}

Ginseng (Panax ginseng C. A. Mey.) belonging to Araliaceae family, is one of the most valuable traditional Chinese herbal medicines, which is distributed mainly in the mountain areas of northeast China, typically in cool wet climates ( $\mathrm{Li}$ et al. 2012; Ying et al. 2012). Due to the good reputation of ginseng for promoting health and general body vigor, and even prolonging life (Jenniferm and Prabashni 2002; Coleman et al. 2003), the economic value of ginseng is relatively high. Naturally grown ginseng in the mountains is regarded as having precious value as a medicine; however, the supply of wild ginseng is far from meeting the demand (Beon et al. 2013). Ginseng is now mainly being planted on mountain sites in the northeast of China, called semi-wide ginseng, where conditions mimic those of naturally grown plants.

The terrain of northeast China is mainly composed of mountains and plains. In the east of Liaoning Province, the average forest coverage rate can reach more than $75 \%$, where the stand types are mainly natural secondary forests and plantations. In this mountainous region, most of the subsistence and economic income can only be acquired from the forests. The Chinese government attaches great importance to the economic development of forests. In 2008, the government carried out the collective forest tenure system reforms, thus allowing farmers to obtain forest management rights and tree ownership. In recent years, the government has actively encouraged the development of a variety of forest management types, especially the underforestry economy (Chang 2009). The Kuandian ShiZhu Ginseng Cultivation System was approved as the first batch of China Nationally Important Agricultural Heritage Systems (China-NIAHS) in 2013, which will actively promote the region's development of ginseng. Globally Important Agricultural Heritage Systems (GIAHS) is sponsored by the Food and Agriculture Organization of the United Nations (FAO) and defined as "remarkable land use systems and landscapes which are rich in biological diversity evolving from the co-adaptation of a community with its environment and its needs and aspirations for sustainable development" (FAO 2008). And China was the first country to carry out the protection of Nationally Important Agricultural Heritage Systems in 2013.

Plant diversity plays a vital role in sustaining human life and the health of our planet. While growing ginseng, one should consider community species composition and structure, including species, density, coverage, etc. In addition, farmers need to clear a certain degree of herbaceous cover to meet the growing space needs of ginseng, which directly influences the diversity of herbaceous plants. On the other hand, the requirement of ginseng cultivation on soil quality is very high, including physical and chemical properties ( $\mathrm{Li}$ and Nai 1994). Ginseng absorbs a large amount of soil nutrients during its growth. Meanwhile, it influences soil properties severely through root exudate profile (Cheng et al. 2011). Plants and soil are interdependent, and each can be affected by alterations in the other (Silva and Batalha 2008; Tang et al. 2015). Plant communities with different composition and diversity can influence the physical and chemical characteristics of soil, and soil properties can also vary vegetation distribution and diversity (Fu et al. 2004; Dybzinski et al. 2008; Eskelinen et al. 2009).

As one forest management type, ginseng cultivation under larch plantations has been widely implemented in the east of Liaoning Province. However, research on the ecological environment influences of this type is still scarce. In order to better implement and promote this valuable plantation type, we try to elucidate the influence of ginseng cultivation under larch plantations on plant diversity and soil properties by comparing the differences among ginseng-larch agroforestry systems (LG), larch plantations (LP) and secondary forests (SF). In addition, we explore the relationship between plant diversity and soil properties based on the three stand types. The objectives are (1) to survey and compare the plant diversity among the three kinds of stand types, (2) to measure and contrast the physical and chemical properties of the soil among the three kinds of stand types, and (3) to quantify the relationships between plant diversity and soil properties in the three kinds of stand types. 


\section{Materials and Methods}

\subsection{Study area}

\subsubsection{Location}

The study area is located in Benxi Manchu Autonomous County of eastern Liaoning Province, northeast China, which belongs to the southeast continuation of the Changbai Mountain range. The site is near the Kuandian ShiZhu Ginseng Cultivation System and is being influenced by the system. The terrain features is mainly composed of mountains where larch-ginseng agroforestry is a main economic source and is practiced on a large scale. The study was conducted in Dongying Fang town which is located at $41^{\circ} 11^{\prime} 52^{\prime \prime}-41^{\circ} 12^{\prime} 30^{\prime \prime}$ north latitudes and $124^{\circ} 29^{\prime} 54^{\prime \prime}-124^{\circ} 33^{\prime} 58^{\prime \prime}$ east longitudes. Within the town, two villages (Nanying Fang and Xiaodong Gou) were chosen for the study. In the Nanying Fang village, there is a ginseng planting cooperative which is very famous in Liaoning Province and the ginseng is cultivated under the larch plantations, so we chose the larchginseng agroforestry system as the study site. Meanwhile, in order to select similar stand conditions as a comparison, we chose the larch plantation and natural secondary forest sites in the Xiaodong Gou village (Figure 1).

\subsubsection{Climate and soil}

The Dongying Fang town is located in the midlatitudes and has a humid mid-temperate climate with strong continental monsoon features including four distinct seasons, abundant rainfall and sunshine, moderate temperatures, bringing rain and heat over the same period. The mean annual air temperature is $6^{\circ} \mathrm{C}-8^{\circ} \mathrm{C}$ and average January
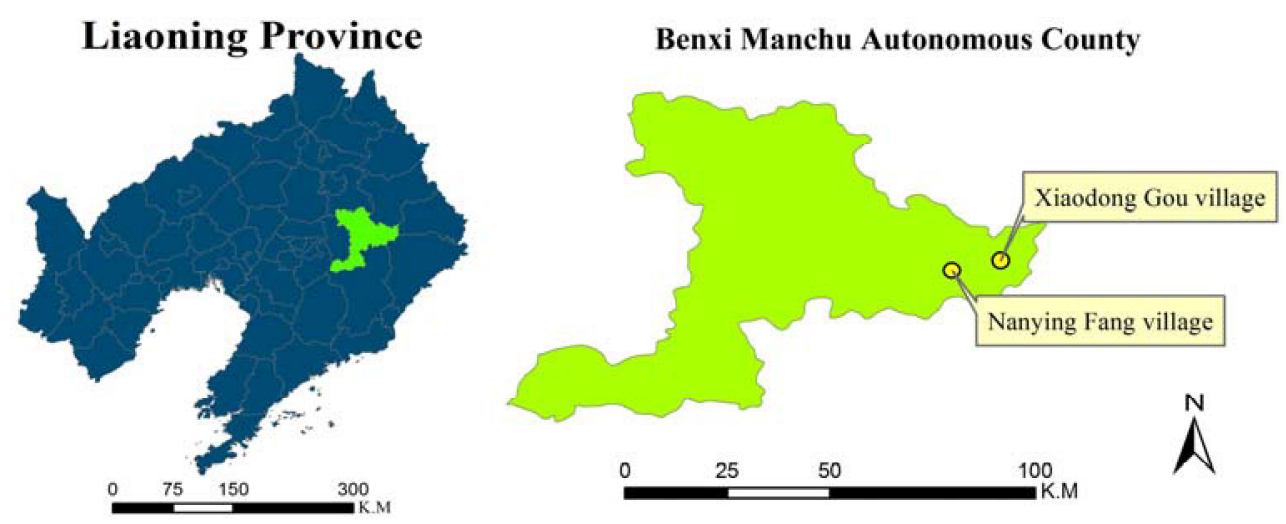

Figure 1 Location of study sites at Nanying Fang and Xiaodong Gou, Benxi Manchu Autonomous County, Liaoning Province, Northeast China. and July air temperature are $-13.5^{\circ} \mathrm{C}$ and $+23 \cdot 3^{\circ} \mathrm{C}$. Annual precipitation ranges from 800 to $1000 \mathrm{~mm}$, of which $61 \%$ falls in July and August. The frostfree period is about 143 days and the mean annual solar period is $2371.8 \mathrm{~h}$. The mean wind speed is 2.1 $\mathrm{m} / \mathrm{s}$ and the mean annual humidity is $67 \%$. The parent material is granite bedrock and the soil is Haplumbrepts (dark brown forest soil in Chinese soil taxonomic system).

Accompanied by the staff of Provincial Academy of Forestry and the County Forestry Bureau, we first went to the cooperative to visit and survey the larch-ginseng agroforestry system in Nanying Fang village. We randomly selected three plots, each of which was $20 \mathrm{~m} \times 30 \mathrm{~m}$ in a total of 10 hectares of planted area. We carefully surveyed and recorded stand characteristics, including age, aspect, slope, altitude, soil type, woody plant density and plant coverage. After that, with the help of the local forestry station manager, we looked for another two kinds of stand types (secondary forest and larch plantation), which had similar stand conditions. In each of the stand types, we also randomly selected three typical $20 \mathrm{~m} \times 30 \mathrm{~m}$ plots and the distance between plots was about 100-500 meters. Site information and specific characteristics of the nine study plots are recorded below (Figure 2, Table 1).

\subsection{Field inventory and laboratory analysis}

\subsubsection{Plant diversity survey}

A forest inventory was carried out in the study area during August, 2014. In total, nine sample plots of the three different kinds of stand types

\subsubsection{Site selection}

\section{Benxi Manchu Autonomous County}




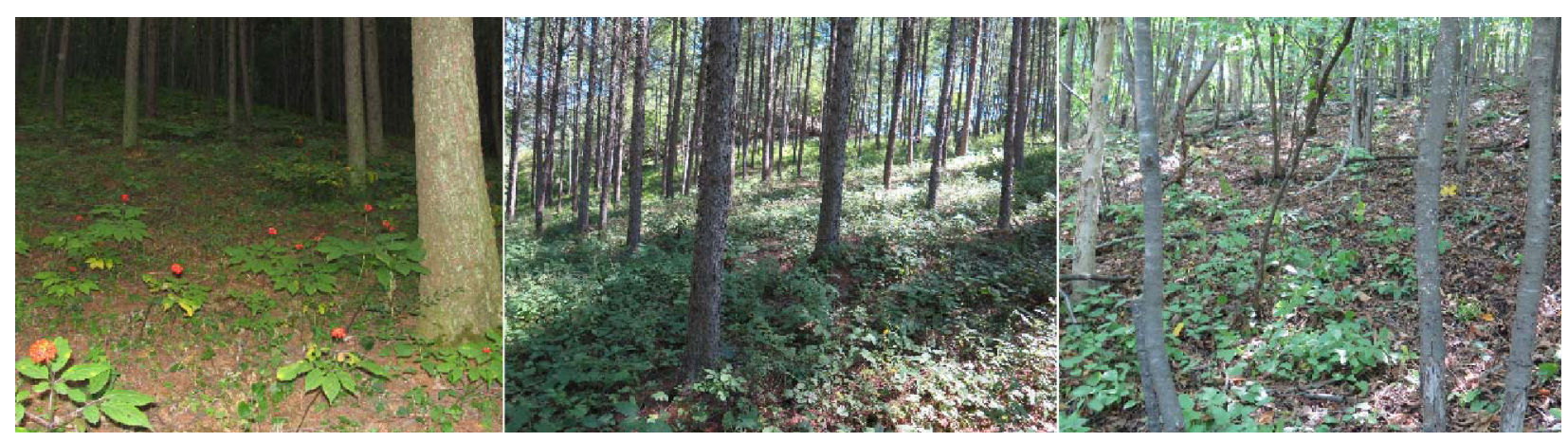

Figure 2 Plots of three kinds of stand types (From left to right respectively Ginseng-Larch agroforestry, Larch plantation, and Secondary forest).

Table 1 The stand characteristics of the nine study plots

\begin{tabular}{l|l|l|l|l|l|l|l|}
$\begin{array}{c}\text { Stand } \\
\text { types }\end{array}$ & No. & SA & $\begin{array}{l}\text { Aspect } \\
\left({ }^{\circ}\right)\end{array}$ & $\begin{array}{l}\text { Slope } \\
\left({ }^{\circ}\right)\end{array}$ & $\begin{array}{l}\text { Alt. } \\
(\mathrm{m})\end{array}$ & WPD & PC \\
\hline \multirow{4}{*}{ LG } & P1 & 32 & NW45 & 14 & 485 & 750 & 0.70 \\
\hline \multirow{5}{*}{ P2 } & 32 & SW40 & 8 & 518 & 833.3 & 0.75 \\
\hline \multirow{2}{*}{ LP } & P3 & 32 & NW60 & 18 & 508 & 716.7 & 0.65 \\
\hline & P5 & 32 & NW5 & 12 & 610 & 850 & 0.75 \\
\hline \multirow{5}{*}{ SF } & P6 & 32 & NW40 & 10 & 542 & 833.3 & 0.75 \\
\hline & P8 & 33 & NE30 & 10 & 540 & 900 & 0.75 \\
\hline & P9 & 33 & NE10 & 16 & 621 & 1016.7 & 0.85 \\
\hline
\end{tabular}

Notes: $\mathrm{LG}=$ Larch-ginseng agroforestry; LP = Larch plantation; $\mathrm{SF}=$ Secondary forest $\mathrm{SA}=$ Stand age (years); WPD = Woody plant density $\left(\right.$ trees $\left./ \mathrm{hm}^{2}\right)$; $\mathrm{PC}=$ Plant coverage.

were surveyed. In each $20 \mathrm{~m} \times 30 \mathrm{~m}$ plot, species name, number, height, diameter at breast height $(\mathrm{DBH} \geq 5 \mathrm{~cm})$ were all investigated and recorded. In each plot, five herb quadrats $(1 \mathrm{~m} \times 1 \mathrm{~m})$ were established according to the observation which represented the plot situation, among which species name, the number of individuals, abundance, coverage of every species were also recorded (Fang et al. 2009). No shrubs were investigated due to their scarcity in the larch-ginseng and larch plantation communities. The plant diversity survey was accomplished with the help of reliable persons with local plant knowledge. All trees and herb species names were identified, later confirmed and recorded according to their botanical name.

\subsubsection{Soil sampling and analysis}

Soil sampling was also carried out at two randomly selected points in each of the nine plots during August, 2014. As the soil layer was not very deep, we determined to collect soil from three depths 0-10, $10-20$ and $20-30 \mathrm{~cm}$ for soil properties. So, a soil pit was dug in each of the 18 points (2 selected points $\times 9$ plots) and each soil pit was about $30 \mathrm{~cm}$ (in length) $\times 30 \mathrm{~cm}$ (in width) $\times 40 \mathrm{~cm}$ (in depth).

For soil properties, we used $100 \mathrm{~cm}^{3}$ cutting ring to collect the soil from the center point in each of the $0-10,10-20$, and $20-30 \mathrm{~cm}$ layers, a total of 54 samples (3 layers $\times 2$ selected $\times 9$ plots) points were collected. The 54 soil samples were weighed and labeled and then transported to the laboratory of the Provincial Academy of Forestry, where they were oven-dried at $105^{\circ} \mathrm{C}$ for $48 \mathrm{~h}$ and again weighed. The bulk density ( $\mathrm{g}$ of dry soil per $\mathrm{cm}^{3}$ of soil) and volumetric soil water content were calculated afterwards. In addition, we used a shovel to take about 250 grams of soil in each of the $0-10$, 10-20, and 20-30 cm layers and put them separately into sealed plastic bags. After being brought back to the laboratory, we pooled to produce composite soil samples.

Thus, a total of 27 composite soil samples (3 layers $\times 9$ plots) were air-dried and stored at $4^{\circ} \mathrm{C}$ ready for chemical properties analysis.

A total of 27 composite soil samples were analyzed. The indictors of soil nutrients included soil organic matter (SOM), total nitrogen (TN), available nitrogen (AN), available potassium (AK) and available phosphorus (AP). SOM was determined by the dichromate oxidation method (Nelson and Sommers 1996). TN was analyzed using the Kjeldahl method (Bremner 1996). AN was extracted with $2 \mathrm{M} \mathrm{KCl}$, AP with a $0.5 \mathrm{M} \mathrm{NaHCO}_{3}$ solution at pH 8.5 (Olsen et al. 1954), and AK with $2 \mathrm{M}$ ammonium acetate at $\mathrm{pH}$ 7.0. Soil $\mathrm{pH}$ was measured in a 1:5 soil-water slurry, using a combination glass electrode. 


\subsection{Data analysis}

\subsubsection{Species diversity}

The species importance values (IV) for trees and herbs were calculated using the following formulas (Fang et al. 2009).

$$
\begin{aligned}
& I V_{\text {tree }}=(R D+R F+R B) / 3 \\
& I V_{\text {herb }}=(R D+R F+R C) / 3
\end{aligned}
$$

Where, $R D$ is the relative density, $R F$ is the relative frequency, $R B$ is the relative breast height diameter, and $R C$ is the relative coverage. The $I V$ value was used to calculate species diversity in each stand type for trees or in each plot for herbs.

The Margalef' species richness index, Shannon-Weiner index, Pielou's equitability index and Sorensen's index were used to assess the plant species diversity (Whittaker 1972; Ma 1994).

$$
\text { Margalef index } R=(N-1) / \ln (n)
$$

Where, $N$ is the number of sampled species, and $n$ is the total number of individuals in the sample.

$$
\text { Shannon-Wiener index } H^{\prime}=-\sum_{i=1}^{s} P_{i} \ln P_{i}
$$

Where, $P_{i}$ is the $I V$ of the $i$ th species in each stand type for trees or in each plot for herbs.

$$
\text { Pielou's equitability index } E=H^{\prime} / \ln S
$$

Where, $S=$ total number of sampled species in each stand type for trees or in each plot for herbs.

Sorensen's index is an index that can describe the difference between two different stand types. The vegetative similarity was estimated by using Sorensen's index of similarity.

$$
\text { Sorensen's index } S I=2 c / a+b
$$

Where, $a$ is the number of species in one stand type, $b$ is the number of species in the other stand type, $c$ is the number of common species in the two stand types.

\subsubsection{Statistical analysis}

To assess differences among the three different stand types, the results of herbaceous species, soil physical and chemical properties were analyzed using one-way ANOVA and LSD tests. Pearson linear correlation analysis was used to examine the correlation relationships between plant diversity and soil properties. All variables were of normal distribution and homogeneity. All the analysis were performed using SPSS 20.0 for Windows.

\section{Results}

\subsection{Plant diversity}

A total of 20 tree species and 37 herbaceous species were identified within the nine sites from three different stand types. For tree species, the number of species in the larch-ginseng agroforestry systems (LG; 7) was equal to the larch plantations (LP; 7), but far fewer than that of the secondary forests (SF; 15). In the LG, there were 7 tree species, of which Larix kaempferi, Lolgensis, Larix principis-rupprechtii and Fraxinus rhynchophylla were the dominant species whose importance values (IV) were more than 0.10. In addition, Larix kaempferi and Lolgensis were the dominant species in the LP, and Acer mono, Betula platyphylla, Juglans mandshurica, Padus maackii and Tilia amurensis were the dominant species in the SF respectively (Table 2). For herbaceous species, the number of species in the larch-ginseng agroforestry systems (LG; 16) was a little lower than that of the larch plantations (LP; 17), but clearly below the secondary forests (SF, 21). In the LG, Panax ginseng and Mosla dianthera were the dominant species, among which the IV of ginseng was up to 0.33 . Adenocaulon himalaicum, Agrimonia pilosa, Platycodon grandiflorus in the LP and Adenocaulon himalaicum, Agrimonia pilosa, Mosla dianthera in the SF were the dominant species respectively (Table 3). Overall, the dominant species were different in the three stand types, except the tree species between LG and LP.

Sorenson's index of similarity showed that the similarity index of tree and herb species was the highest between LG and LP, and the lowest between LG and SF. In addition, the similarity index ranged from 0.57 to 0.18 among tree species, and from 0.48 to 0.32 among herb species (Figure 3).

In order to obtain a better picture of plant species diversity, various diversity indices were calculated for the three different stand types (Figure 4). For tree species, the Shannon index ( $\left.\mathrm{H}^{\prime}\right)$, Pielou's equitability index (E) and Margalef index (R) decreased in the order of SF, LG and LP. But for herbaceous species, $H^{\prime}, E$ and $R$ values decreased in the order of SF, LP and LG. In addition, the 
Table 2 The species importance values of herbs among the three different kinds of stand types

\begin{tabular}{|c|c|c|c|c|c|}
\hline LG & IV & LP & IV & $\mathrm{SF}$ & IV \\
\hline Actinidia kolomikta & 0.05 & Actinidia kolomikta & 0.03 & Aconitum carmichaeli & 0.03 \\
\hline Adenocaulon himalaicum & 0.09 & Adenocaulon himalaicum & 0.29 & Actinidia kolomikta & 0.05 \\
\hline Agastache rugosa & 0.03 & Agrimonia pilosa & 0.12 & Adenocaulon himalaicum & 0.11 \\
\hline Agrimonia pilosa & 0.04 & Anemone chinensis & 0.01 & Aegopodium alpestre & 0.09 \\
\hline Artemisia argyi & 0.01 & Artemisia argyi & 0.04 & Agrimonia pilosa & 0.10 \\
\hline Atractylodes Lancea & 0.03 & Delphinium grandiflorum & 0.02 & Angelica sieboldi & 0.09 \\
\hline Chelidonium majus & 0.04 & Dioscorea nipponica & 0.03 & Cimicifugae foetida & 0.04 \\
\hline Glycine soja & 0.05 & Doellingeria scaber & 0.01 & Delphinium grandiflorum & 0.02 \\
\hline Humulus scandens & 0.01 & Glycine soja & 0.02 & Dioscorea nipponica & 0.03 \\
\hline Imperata cylindrica & 0.05 & Juncus effuses & 0.03 & Impatiens noli-tangere & 0.01 \\
\hline Leontopodium & 0.01 & Mosla dianthera & 0.09 & Juncus effuses & 0.02 \\
\hline Mosla dianthera & 0.21 & Murdannia triguetra & 0.03 & Leonurus artemisia & 0.04 \\
\hline Murdannia triguetra & 0.03 & Rhizoma Arisaematis & 0.08 & Lilium distichum & 0.02 \\
\hline Nettle & 0.01 & Physalis alkekengi & 0.04 & Mosla dianthera & 0.15 \\
\hline Panax ginseng & 0.33 & Platycodon grandiflorus & 0.10 & Murdannia triguetra & 0.02 \\
\hline \multirow[t]{6}{*}{ Platycodon grandiflorus } & 0.01 & Potentilla multicaulis & 0.04 & Platycodon grandiflorus & 0.10 \\
\hline & & Semen plantaginis & 0.02 & Poa апnua & 0.01 \\
\hline & & & & Rubia cordifolia & 0.04 \\
\hline & & & & Schisandra chinensis & 0.01 \\
\hline & & & & Thalictrum aquilegifolium & 0.01 \\
\hline & & & & Viola verecumda & 0.01 \\
\hline
\end{tabular}

Notes: $\mathrm{LG}=$ Ginseng cultivation under larch plantations; IV = Importance value; $\mathrm{LP}=$ Larch plantation; $\mathrm{SF}=$ Natural secondary forests.

Table 3 The species importance values of trees among the three different kinds of stand types

\begin{tabular}{|c|c|c|c|c|c|}
\hline LG & IV & LP & IV & $\mathrm{SF}$ & IV \\
\hline Fraxinus rhynchophylla & 0.10 & Acer mono & 0.04 & Acer mono & 0.11 \\
\hline Hemiptelea davidii & 0.03 & Carpinus cordata & 0.04 & Acer tegmentosum & 0.05 \\
\hline Larix kaempferi & 0.32 & Fraxinus rhynchophylla & 0.04 & Amur cork & 0.03 \\
\hline Larix principis-rupprechtii & 0.13 & Juglans mandshurica & 0.07 & Betula platyphylla & 0.13 \\
\hline Larix Lolgensis & 0.32 & Larix kaempferi & 0.47 & Bothrocaryum controversum & 0.06 \\
\hline Pirus & 0.07 & Larix Lolgensis & 0.29 & Carpinus cordata & 0.09 \\
\hline \multirow[t]{9}{*}{ Xylosma racemosum } & 0.03 & Xylosma racemosum & 0.05 & Fraxinus mandschurica & 0.03 \\
\hline & & & & Fraxinus rhynchophylla & 0.05 \\
\hline & & & & Juglans mandshurica & 0.11 \\
\hline & & & & Maackia amurensis & 0.01 \\
\hline & & & & Padus maackii & 0.15 \\
\hline & & & & Populus davidiana & 0.02 \\
\hline & & & & Syring a reticulata & 0.01 \\
\hline & & & & Tilia amurensis & 0.12 \\
\hline & & & & Xylosma racemosum & 0.03 \\
\hline
\end{tabular}

diversity indices were significantly lower in LG than in SF. For herbs, there was no significant difference between LG and LP, except the value of E. The difference was also not significant between LP and $\mathrm{SF}$, except the value of $\mathrm{H}^{\prime}$.

\subsection{Soil properties}

Soil bulk density increased gradually along with depth in the three stand types. In each layer, the value of LG was the highest and SF was the lowest. The difference of bulk density between LG and LP was not significant, but the bulk density was significantly higher in LG than in SF. In addition, soil maximum moisture, capillary moisture and total porosity also increased along with depth in the three stand types. According to the order from small to large in each layer were LG, LP and SF. The difference between LG and LP was also not significant, but the difference was significant between LG and SF. However, the changes of capillary porosity and non-capillary porosity along with depth were complex, and there were no significant differences among the three stand types 


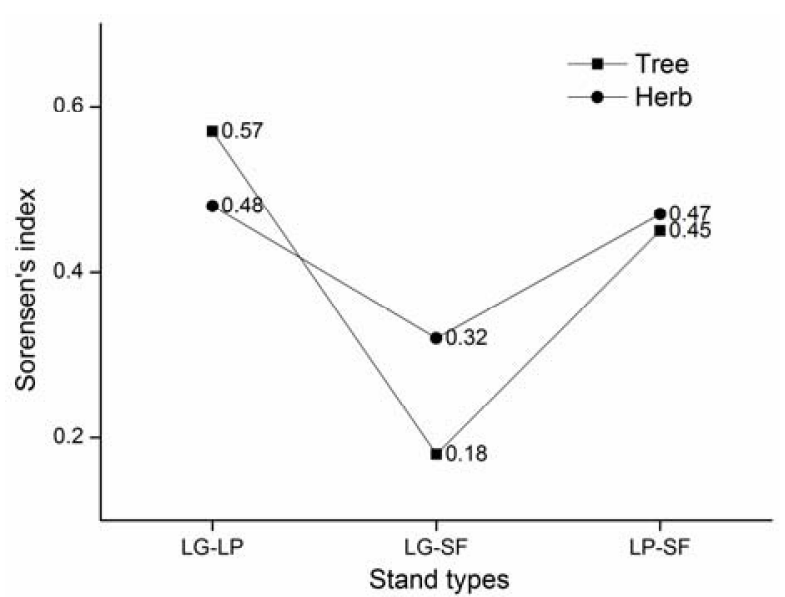

Figure 3 The similarity of plant species among the three kinds of stand types.
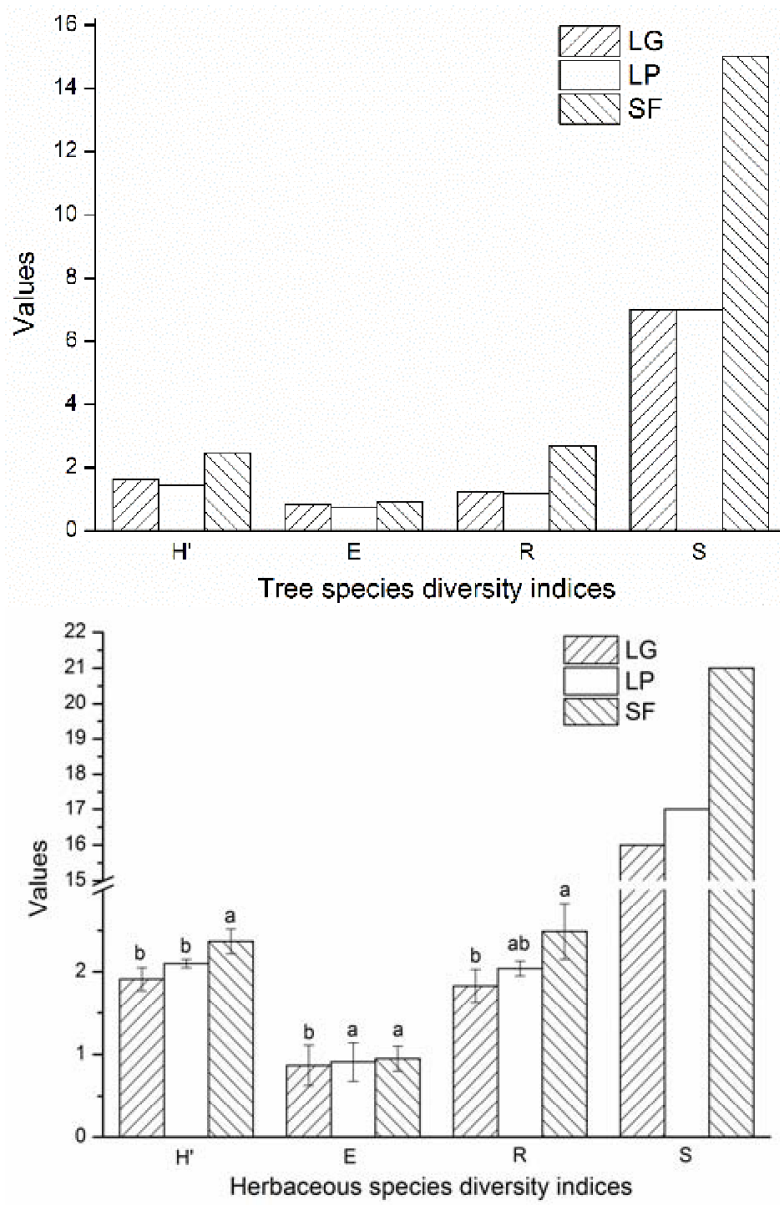

Figure 4 Indices of the tree and herbaceous species diversity among the three kinds of stand types. Different letters $(a, b)$ indicate significant differences between stand types $(p<0.05)$, and the error bars depict standard errors of the mean.

\section{(Table 4).}

Along with the depth from the 0-10, 10-20, and
20-30 cm, SOM, TN, AN and AK showed a downward trend, but $\mathrm{AP}$ and $\mathrm{pH}$ showed no obvious changes. For SOM, according to the order from small to large in each layer were LG, LP and SF. Furthermore, there was no significant difference between LG and LP, except in the 10-20 $\mathrm{cm}$ layer. And no significant difference was found between LP and SF, but LG was significantly lower than SF. For TN and AN, the content in LG was also the lowest, and the contents in LP and SF were approximately the same. Moreover, LG had a significant difference with LP and SF. For AP, the values gradually decreased basically along with depth. LP had the highest content of AP in each layer, and was significantly higher than LG and SF in the $0-10$ and $20-30 \mathrm{~cm}$. For AK, according to the order from small to large in each layer were also LG, $\mathrm{LP}$ and SF, except the $\mathrm{o}-10 \mathrm{~cm}$ layer. For $\mathrm{pH}$, the values ranged from 5.08 to 5.27, and there were no significant differences among the different layers and stand types (Table 5).

\subsection{Correlations between plant diversity ( $\left.\mathrm{H}^{\prime}\right)$ and soil properties}

Correlation analysis was used to examine the relationships between soil properties and plant diversity as listed in Table 6 . The soil properties of o$10 \mathrm{~cm}$ and $0-30 \mathrm{~cm}$ were analyzed, and plant Shannon diversity included tree and herbaceous diversity. The relationship between soil properties in the $0-10 \mathrm{~cm}$ and tree diversity was generally weak $(P>0.05)$. And the relationship between soil properties in the $0-30 \mathrm{~cm}$ and tree diversity was also weak $(P>0.05)$, except the significant relationship between non-capillary porosity and tree diversity $(P<0.05)$. Compared with the weak relationship between soil properties and tree diversity, the relationship between soil properties and herbaceous diversity was stronger. For soil properties in the o$10 \mathrm{~cm}$, a significant relationship with herbaceous diversity was shown by maximum moisture, noncapillary porosity, TN and AN (positive), as well as by bulk density (negative) $(P<0.01)$. For soil properties in the $0-30 \mathrm{~cm}$, there was a more significant relationship with herbaceous diversity. Among them, bulk density showed a negative relationship and maximum moisture presented a highly positive relationship $(P<0.01)$. Furthermore, Capillary moisture, Total porosity, Non-capillary porosity, SOM, TN, AN, AK had a positive 
Table 4 The physical properties of soil among the three kinds of stand types

\begin{tabular}{|c|c|c|c|c|c|c|}
\hline Stand type & $\begin{array}{l}\text { Bulk density } \\
\left(\mathrm{g} / \mathrm{cm}^{3}\right)\end{array}$ & $\begin{array}{l}\text { Maximum } \\
\text { moisture (\%) }\end{array}$ & $\begin{array}{l}\text { Capillary } \\
\text { moisture (\%) }\end{array}$ & $\begin{array}{l}\text { Total } \\
\text { porosity (\%) }\end{array}$ & $\begin{array}{l}\text { Capillary } \\
\text { porosity (\%) }\end{array}$ & $\begin{array}{l}\text { Non-capillary } \\
\text { porosity (\%) }\end{array}$ \\
\hline \multicolumn{7}{|c|}{ at $0-10 \mathrm{~cm}$ soil depth } \\
\hline LG & $0.99( \pm 0.09) a$ & $50.85( \pm 9.58) \mathrm{b}$ & $41.20( \pm 5.64) b$ & $54.17( \pm 4.07) b$ & $44.22( \pm 4.53) \mathrm{a}$ & $9.95( \pm 3.76) b$ \\
\hline LP & $0.92( \pm 0.06) a$ & $58.34( \pm 12.50) b$ & $47.14( \pm 12.41) a b$ & $55 \cdot 77( \pm 7.17) b$ & $44.93( \pm 8.29) a$ & $10.83( \pm 2.26) b$ \\
\hline SF & $0.81( \pm 0.06) b$ & $77.10( \pm 5.16) \mathrm{a}$ & $54.64( \pm 7.81) a$ & $63.08( \pm 1.95) \mathrm{a}$ & $44.83( \pm 7.13) a$ & $18.25( \pm 6.45) \mathrm{a}$ \\
\hline \multicolumn{7}{|c|}{ at $10-20 \mathrm{~cm}$ soil depth } \\
\hline LG & $1.10( \pm 0.09) a$ & $49.83( \pm 9.42) b$ & $41.61( \pm 6.21) \mathrm{b}$ & $53.47( \pm 3.83) \mathrm{b}$ & $44.87( \pm 2.76) \mathrm{a}$ & $8.6( \pm 4.09) a b$ \\
\hline LP & $0.99( \pm 0.10) a b$ & $53.67( \pm 13.21) \mathrm{b}$ & $47.56( \pm 11.68) a b$ & $53.13( \pm 5.67) b$ & $47.25( \pm 6.59) \mathrm{a}$ & $5.88( \pm 4.30) b$ \\
\hline $\mathrm{SF}$ & $0.89( \pm 0.08) b$ & $66.50( \pm 7.51) a$ & $52.20( \pm 6.43) a$ & $60.05( \pm 4.21) \mathrm{a}$ & $47.27( \pm 5.24) a$ & $12.78( \pm 3.15) \mathrm{a}$ \\
\hline \multicolumn{7}{|c|}{ at $20-30 \mathrm{~cm}$ soil depth } \\
\hline LG & $1.18( \pm 0.06) \mathrm{a}$ & $45.86( \pm 3.46) b$ & $36.34( \pm 4.17) \mathrm{b}$ & $50.20( \pm 3.31) b$ & $39.88( \pm 5.24) \mathrm{a}$ & $10.32( \pm 3.00) a$ \\
\hline LP & $1.07( \pm 0.10) a b$ & $50.53( \pm 8.21) \mathrm{b}$ & $43.32( \pm 9.53) \mathrm{ab}$ & $51.28( \pm 5.92) \mathrm{b}$ & $43.93( \pm 8.17) a$ & $7.35( \pm 4.54) a$ \\
\hline SF & $0.97( \pm 0.10) b$ & $64.57( \pm 13.17) a$ & $50.07( \pm 7.68) \mathrm{a}$ & $59.10( \pm 5.01) a$ & $46.32( \pm 5.11) a$ & $12.78( \pm 9.20) \mathrm{a}$ \\
\hline
\end{tabular}

Notes: Different letters $(\mathrm{a}, \mathrm{b})$ indicate significant differences between stand types $(p<0.05)$. Standard errors are presented in parentheses. The same for Table 5 .

Table 5 The chemical properties of soil among the three kinds of stand types

\begin{tabular}{|c|c|c|c|c|c|c|}
\hline Stand type & SOM (g/kg) & $\mathrm{TN}(\mathrm{g} / \mathrm{kg})$ & $\mathrm{AN}(\mathrm{mg} / \mathrm{kg})$ & AP (mg/kg) & $\mathrm{AK}(\mathrm{mg} / \mathrm{kg})$ & $\mathrm{pH}$ \\
\hline \multicolumn{7}{|c|}{ at $0-10 \mathrm{~cm}$ soil depth } \\
\hline LG & $63.81( \pm 12.14) b$ & $3.02( \pm 0.63) b$ & $340.04( \pm 33.36) b$ & $13.81( \pm 2.09) \mathrm{b}$ & $146.17( \pm 41.4) b$ & $5.08( \pm 0.05) \mathrm{a}$ \\
\hline LP & $85.20( \pm 10.74) a b$ & $4.15( \pm 0.49) a$ & $472.94( \pm 20.76) a$ & $19.00( \pm 0.45) \mathrm{a}$ & $145.83( \pm 12.95) b$ & $5.08( \pm 0.09) \mathrm{a}$ \\
\hline SF & $105 \cdot 31( \pm 15 \cdot 56) a$ & $4.96( \pm 0.42) a$ & $510.34( \pm 30.64) a$ & $15.80( \pm 2.58) a b$ & $252.00( \pm 30.90) a$ & $5.17( \pm 0.17) a$ \\
\hline \multicolumn{7}{|c|}{ at $10-20 \mathrm{~cm}$ soil depth } \\
\hline LG & $41.69( \pm 3.48) b$ & $2.07( \pm 0.22) b$ & $207.58( \pm 22.40) b$ & $14.07( \pm 2.00) \mathrm{a}$ & $73.83( \pm 6.50) b$ & $5.27( \pm 0.08) \mathrm{a}$ \\
\hline LP & $58.10( \pm 7.70) a$ & $3.25( \pm 0.64) a$ & $393.33( \pm 57.40) a$ & $16.98( \pm 2.12) a$ & $116.00( \pm 23.56) \mathrm{a}$ & $5.11( \pm 0.06) \mathrm{a}$ \\
\hline SF & $64.79( \pm 3 \cdot 30) a$ & $3.43( \pm 0.54) \mathrm{a}$ & $364.90( \pm 50.14) a$ & $13.17( \pm 0.36) a$ & $140.33( \pm 24.06) a$ & $5.14( \pm 0.10) a$ \\
\hline \multicolumn{7}{|c|}{ at $20-30 \mathrm{~cm}$ soil depth } \\
\hline LG & $31.14( \pm 5.82) \mathrm{b}$ & $1.38( \pm 0.19) b$ & $148.91( \pm 19.17) b$ & $13.04( \pm 0.20) b$ & $46.17( \pm 4.80) b$ & $5.25( \pm 0.16) a$ \\
\hline LP & $39.57( \pm 4.37) a b$ & $2.50( \pm 0.55) \mathrm{a}$ & $298.83( \pm 68.10) a$ & $15.51( \pm 1.97) \mathrm{a}$ & $97.83( \pm 23.16) \mathrm{a}$ & $5.11( \pm 0.11) \mathrm{a}$ \\
\hline SF & $46.38( \pm 4.18) \mathrm{a}$ & $2.37( \pm 0.22) a$ & $256.86( \pm 21.46) \mathrm{a}$ & $12.76( \pm 0.20) b$ & $110.83( \pm 14.63) a$ & $5.18( \pm 0.10) a$ \\
\hline
\end{tabular}

relationship with herbaceous diversity $(P<0.05)$.

\section{Discussion}

\subsection{The type of ginseng cultivation under larch}

In recent years, especially after the collective forest tenure system reforms, farmers' enthusiasm for cultivating ginseng has been quite high because of the good economic benefits. The area of ginseng cultivation under larch plantations has increased noticeably, because most of the forests distributed to the farmers were plantations. However, the quality of ginseng cultivation under larch is lower compared with ginseng cultivation under broad-leaved mixed forest and theropencedrymion (Chen et al. 2005). The reasons are that higher species diversity of plant communities can increase the negative entropy flow in the system, so as to form a stable,
Table 6 Pearson correlation coefficients between plant diversity $\left(\mathrm{H}^{\prime}\right)$ and soil properties among the three kinds of stand types

\begin{tabular}{|l|l|l|l|l|}
\hline \multirow{2}{*}{ Soil Properties } & \multicolumn{2}{|c|}{ Tree } & \multicolumn{2}{c|}{ Herbaceous } \\
\hline Bulk density & $0-10 \mathrm{~cm}$ & $0-30 \mathrm{~cm}$ & $0-10 \mathrm{~cm}$ & $0-30 \mathrm{~cm}$ \\
\hline Maximum moisture & -0.84 & -0.79 & $-0.9^{* *}$ & $-0.88^{* *}$ \\
\hline Capillary moisture & 0.9 & 0.91 & $0.83^{* *}$ & $0.85^{* *}$ \\
\hline Total porosity & 0.81 & 0.77 & 0.64 & $0.73^{*}$ \\
\hline Capillary porosity & 0.94 & 0.97 & 0.66 & $0.78^{*}$ \\
\hline Non-capillary porosity & 0.23 & 0.56 & 0 & 0.37 \\
\hline SOM & 0.97 & $1^{*}$ & $0.8^{* *}$ & $0.72^{*}$ \\
\hline TN & 0.74 & -0.58 & 0.59 & $0.76^{*}$ \\
\hline AN & 0.71 & 0.63 & $0.69^{* *}$ & $0.79^{*}$ \\
\hline AP & 0.54 & 0.29 & $0.69^{* *}$ & $0.72^{*}$ \\
\hline AK & -0.3 & 0.52 & 0.1 & -0.04 \\
\hline pH & 0.99 & 0.84 & 0.6 & $0.77^{*}$ \\
\hline
\end{tabular}

Notes: Correlation is significant at ${ }^{*} P<0.05$ (2-tailed), ${ }^{*} P<0.01$ (2-tailed). 
orderly dissipative structure, which is conducive to ginseng growth and development ( $\mathrm{Li}$ and $\mathrm{Zhu}$ 1998; Chandler 2015); and that soil nutrients are more depleted here than under broad-leaved mixed forest and theropencedrymion (Kim et al. 2015). In addition, according to the survey of the farmers, only a few of them obtained high economic benefits because of their lack of ginseng cultivation management experience, especially the influence of ginseng rust rot disease.

\subsection{Implications of Ginseng cultivation under larch for plant diversity}

As for the productive mode of larch-ginseng agroforestry, the normal management by farmers does not intentionally influence the tree diversity, so the tree diversity between larch-ginseng agroforestry and larch plantation is approximate. In addition, the tree density and coverage are crucial to the growth of ginseng. According to the field survey, the tree density and coverage in LG were 750 trees $/ \mathrm{hm}^{2}$ and 0.70 respectively, which were generally lower than the LP and SF (Table 1). The reason is that farmers carried out the silvicultural operations, like thinning on a certain degree, in order to satisfy the space and illumination needs of ginseng.

As for herbaceous diversity, the index of $\mathrm{H}^{\prime}$ and $\mathrm{R}$ between LG and LP showed no significant difference, and the species richness was also similar. However, the species evenness (E) in LG was significantly lower than in LP. In addition, the IV of ginseng was 0.33 in LG, which was clearly higher than other species. The reasons mainly lie in the planting management by local farmers. In general, farmers remove some weeds to satisfy the growth of ginseng. Thus ginseng naturally becomes the dominant species in the community and the index of $\mathrm{E}$ was lower than in the other two stand types.

In addition, no matter tree or herbaceous cover, the $\mathrm{H}^{\prime}, \mathrm{R}$ and $\mathrm{S}$ in SF were clearly higher than in LG and LP. Therefore, paying more attention to the protection of natural secondary forest is of great significance for the maintenance of plant diversity (Liu et al. 2013).

\subsection{Implications of ginseng cultivation under larch for soil properties}

This study revealed notable differences in the soil properties among the three different stand types. From the perspective of soil depth, the bulk density increased gradually along with depth, but maximum moisture, capillary moisture, total porosity and non-capillary porosity were on the opposite. The reason is that soil gradually becomes compacted with depth. From the perspective of stand types, there was no significant difference between LG and LP, which showed ginseng cultivation had no obvious effect on soil physical properties. But a significant difference was found between natural secondary forests (SF) and plantations (LG and LP). The bulk density in LG was higher than in SF, which may be due to a low organic C content in LG compared with SF because the soil bulk density was affected by soil organic C content (Cromack 1999). Also the maximum and capillary moisture were due to the high organic C content that directly and indirectly influenced the soil water content (Kim et al. 2015). For capillary porosity, there was no significant difference among the three different stand types, because they are of the same soil type. However, the total porosity and non-capillary porosity in SF were significantly higher than in LG and LP. The reason may be that the plant diversity and the roots of plants had a bigger impact on the soil in SF than in LG and LP.

From the perspective of soil depth, SOM, TN, $\mathrm{AN}$ and AK showed an obvious downward trend. This is mainly due to the surface layer soil nutrients presenting a cluster phenomenon that vegetation litter, root secretion and biological residue mainly aggregate in the surface soil. The SOM, TN and AN were lower in LG than in LP and SF. Moreover, natural secondary forests (SF) was much higher than plantations (LG and LP), and SF and LP were significantly higher than LG. According to the results, we can conclude that the high SOM in SF may be due to the increased sources of SOM from the litter fluxes compared with the slowly decomposing litter in plantations (Fisher and Dan 2013). In addition, the reason why SOM, TN and AN were significantly higher in LP than in LG is due to the cultivation practices of ginseng. As a perennial herb, ginseng would absorb a lot of nutrients which is serious for the maintenance of soil fertility (Li and Nai 1994). AP was medium in all of the three stand types. This content may be due to decreased $\mathrm{P}$ availability in acidified soils 
(Fisher and Dan 2013). There were no obvious changes with depth and not too much difference among the stand types. The significant difference between LG and LP may also be due to the cultivation practice of ginseng. The content of $\mathrm{AK}$ in LG was relatively low except in the $0-10 \mathrm{~cm}$ layer, and the content of AK in LP and SF were medium. Soil $\mathrm{pH}$ is an important soil environmental factor for plant growth. On mountain slopes, rainfall leaches out the basic minerals in soils, and tends to speed this acidulation process (Sharpley et al. 1992; Cart et al. 1998). No obvious difference was found among the three different stand types, and soil pH ranged from 5.08 to 5.27 , which is relatively low.

\subsection{Relationships between plant diversity and soil properties}

Currently, numerous studies involving the relationships between plant diversity and soil properties have been conducted (Dezzeo 2004). Although the results are not completely consistent, the correlations between them have been widely recognized (Mlambo 2005; Sang 2009). In our study, firstly we can conclude that the correlation relationships between soil properties and tree diversity were lower than that between soil properties and herb diversity. Moreover, there is a more significant relationship between plant diversity and soil in the $0-30 \mathrm{~cm}$ level than that in the $0-10 \mathrm{~cm}$ level. Based on the analysis of the relationship between soil properties in $0-30 \mathrm{~cm}$ and tree Shannon diversity, only non-capillary porosity had a statistically significant correlation relationship. However, according to the analysis of the relationship between soil properties in the 0-30 $\mathrm{cm}$ and herbs Shannon diversity, both physical and chemical properties of the soil had significant correlations with herbs, except capillary porosity, $\mathrm{AP}$ and $\mathrm{pH}$. Thus, we can conclude that herbaceous plant diversity has an effect on the improvement of soil structure, and maintenance of good soil structure is beneficial to plant diversity. In addition, soil nutrients are crucial to the growth of herbs and the herbaceous plant diversity. Thus maintenance or enhancement of soil organic matter and nitrogen

\section{Acknowledgements}

The study was financially supported by the content is necessary for increasing herbaceous plant diversity and plant growth.

\section{Conclusion}

The results showed significant difference in the plant diversity between natural secondary forests (SF) and plantations (LG and LP). However, no obvious differences in $\mathrm{H}^{\prime}, \mathrm{R}$ and $\mathrm{S}$ between $\mathrm{LG}$ and LP were found, which suggest ginseng cultivation under larch plantation has no obvious effect on plant diversity. But the evenness of herbs in the community was influenced by ginseng cultivation.

Soil physical and chemical properties presented a clear change along with depth. There are significant difference between natural secondary forests (SF) and plantations (LG and LP), which may explain why plant diversity has an obvious influence on soil properties. In addition, based on the contrast between LG and LP, we can conclude that ginseng cultivation has no obvious effect on soil physical properties, but has a deleterious effect on soil fertility. Therefore, appropriate supplements to maintain and enhance soil fertility are needed in LG.

The correlations between plant diversity and soil properties are evident, especially that between herbaceous plant diversity and soil properties. Based on our study, we can find that plant diversity is conducive to the improvement of soil structure and an increase in soil fertility. Therefore, to maintain the diversity of herbaceous plants and control the densities of ginseng, appropriate management by farmers is important during the process of ginseng cultivation under larch.

As one kind of forest management type, larchginseng agroforestry has no obvious adverse effect on the ecological environment. In addition, due to the influence of topography and landscape, making full use of the space under the forest is of great significance for the improvement of farmers' economic benefits in the Changbai Mountain region. In view of these good comprehensive benefits and with the support of policy, this mode of production should be promoted moderately in the future.

research on soft science of forestry (2014-Ro5) and 
consulting project of the Chinese Academy of Engineering (2013-XZ-22). Many thanks go to the local forest managers and farmers, LIU Jing-quan,

\section{References}

Beon MS, Park JH, Kang HM, et al. (2013) Geographic information system-based identification of suitable cultivation sites for wood-cultivated ginseng. Journal of Ginseng Research 37(4): 491-495. DOI: 10.5142/jgr.2013. 37.491

Bremner JM (1996) Nitrogen total. In: Sparks DL (ed.), Methods of soil analysis. Part 3 - chemical methods. Soil Science Society of America Inc, Madison, USA. pp 10851121.

Catt JA, Howse KR, Farina R, et al. (1998) Phosphorus losses from arable land in England. Soil Use and Management 14(s4): 168-174. DOI: 10.1111/j.1475-2743.1998.tboo636.x

Chandler JL, McGraw JB (2015) Variable effects of timber harvest on the survival, growth, and reproduction of American ginseng (Panax quinquefolius L.). Forest Ecology and Management 344: 1-9. DOI: 10.1016/j.foreco.2015.02. 007

Chen HW, Yin MF, Liu N, et al. (2005) A study on community's structure and characteristics of herbage layer planting ginsengs under forest in mountain areas in Eastern Liaoning. Journal of Northwest Forestry University 20(2): 61-63. (In Chinese)

Cheng HT, Zhang YY, Zhang LX, et al. (2011) Changes of soil nutrients in ginseng under forest at different growth stages. Chinese Agricultural Science Bulletin 27(8): 47-52. (In Chinese)

Coleman CI, Hebert JH, Reddy P (2003) The effects of Panax ginseng on quality of life. Journal of Clinical Pharmacy and Therapeutics 28(1): 5-15. DOI: 10.1046/j.1365-2710.2003. 00467.x

Cromack K, Miller RE, Anderson HW, et al. (1999) Soil carbon and nutrients in a coastal Oregon Douglas-fir plantation with red alder. Soil Science Society of America Journal 63(1): 232-239. DOI: 10.2136/sssaj1999.036159950063 $00010034 \mathrm{x}$

Dezzeo N, Chacón N, Sanoja E, et al. (2004) Changes in soil properties and vegetation characteristics along a forestsavanna gradient in southern Venezuela. Forest Ecology and Management 200(s1-3): 183-193. DOI: 10.1016/ j.foreco.2004.06.016

Dybzinski R, Fargione JE, Zak DR, et al. (2008) Soil fertility increases with plant species diversity in a long-term biodiversity experiment. Oecologia 158(1): 85-93. DOI: 10.1007/s00442-008-1123-x

Eskelinen, A, Stark S, Männistö M (2009) Links between plant community composition, soil organic matter quality and microbial communities in contrasting tundra habitats. Oecologia 161(1): 113-123. DOI: 10.1007/s00442-009-1362-5

Fang JY, Wang XP, Shen ZH, et al. (2009) Methods and protocols for plant community inventory. Biodiversity Science 17 (6): 533-548. (In Chinese). DOI: 10.3724/SP.J. 1003.2009.09253

Fisher R F, Dan B (2013) Forest Biogeochemistry. Ecology and Management of Forest Soils, Fourth Edition. John Wiley \& Sons, Ltd, USA. pp 99-137.

Fu BJ, Liu SL, Ma KM, et al. (2004) Relationships between soil characteristics, topography and plant diversity in a heterogeneous deciduous broad-leaved forest near Beijing, China. Plant and Soil 261(1): 47-54.

Jenniferm E, Prabashni R (2002) Effects of Panax ginseng on quality of life. Annals of Pharmacotherapy 36(3): 375-379.
SONG Xiao-guang, XIE Ting-ku et al., for their help in the field survey.

DOI: 10.1161/ATVBAHA.109.191759

Kim C, Choo GC, Cho HS, et al. (2015) Soil properties of cultivation sites for mountain-cultivated ginseng at local level. Journal of Ginseng Research 39(1): 76-80. DOI: 10.1016/j.jgr.2014.06.004

Li D, Zhu LH, Li HB (1998) A preliminary study on understory plant diversity among several major forest types in the eastern mountain area of Liaoning. Journal of Liaoning Forestry Science and Technology 6: 40-42. (In Chinese)

Li WH, Lai SD (1994) Agroforestry in China. Science Press, Beijing, China. p. 187. (In Chinese)

Li Y, Ying YX, Zhao DY, et al. (2012) Microbial community diversity analysis of Panax ginseng rhizosphere and nonrhizosphere soil using randomly amplified polymorphic DNA method. Open Journal of Genetics 2(2): 95-102. DOI: 10.4236/ojgen.2012.22014

Liu SR, Innes J, Wei XH (2013) Shaping forest management to climate change: an overview. Forest Ecology and Management 300(4): 1-3. DOI:10.1016/j.foreco.2013.02.018

Ma KP (1994) Measurement of biotic community diversity I. alpha diversity (Part 1). Chinese Biodiversity 2(3): 162-168. (In Chinese)

Mlambo D, Nyathi P, Mapaure I (2005) Influence of Colophospermum mopane on surface soil properties and understorey vegetation in a southern African savanna. Forest Ecology and Management 212(s1-3): 394-404. DOI: 10.1016/j.foreco.2005.03.022

Nelson DW, Sommers LE (1996) Total carbon, organic carbon, and organic matter. In: Sparks DL (ed.), Methods of soil analysis. Part 3 - chemical methods. Soil Science Society of America Inc, Madison, USA. pp 961-1010.

Olsen SR, CV Cole, FS Watanabe, et al. (1954) Estimation of available phosphorus in soils by extraction with sodium bicarbonate. USDA Circular 939: 1-19.

Sang WG (2009) Plant diversity patterns and their relationships with soil and climatic factors along an altitudinal gradient in the middle Tianshan Mountain area, Xinjiang, China. Ecological Research 24(2): 303-314. DOI: 10.1007/s11284008-0507-z

Sharpley AN, Smith SJ, Jones OR, et al. (1992) The transport of bioavailable phosphorus in agricultural runoff. Journal of Environmental Quality 21(1): 30-35. DOI: 10.2134/jeq1992. $00472425002100010003 x$

Silva DMD, Batalha MA (2008) Soil-vegetation relationships in cerrados under different fire frequencies. Plant and Soil 311: 87-96. DOI: $10.1007 /$ s11104-008-9660-y

Tang L, Dong SK, Liu SL, et al. (2015) The relationship between soil physical properties and alpine plant diversity on Qinghai-Tibet Plateau. Eurasian Journal of Soilence 4(2): 88-93. DOI: $10.18393 /$ ejss.31228

Whittaker RH (1972) Evolution and measurement of species diversity. Taxon 21(2/3): 213-251. DOI: $10.2307 / 1218190$

Ying YX, Ding WL, Zhou YQ, et al. (2012) Influence of Panax ginseng continuous cropping on metabolic function of soil microbial communities. Chinese Herbal Medicines 4(4): 329-334. DOI: 10.3969/j.issn.1674-6384.2012.04.011

Youn YC (2009) Use of forest resources, traditional forestrelated knowledge and livelihood of forest dependent communities: Cases in South Korea. Forest Ecology and Management 257(10): 2027-2034. DOI: 10.1016/j.foreco. 2009.01.05 